\title{
Paternal radiation exposure and leukaemia in offspring: the Ontario case-control study
}

\author{
John R McLaughlin, Will D King, Terence W Anderson, E Aileen Clarke, J Patrick Ashmore
}

\begin{abstract}
Objectives-To test the hypothesis that there is an association between childhood leukaemia and the occupational exposure of fathers to ionising radiation before a child's conception.

Design-Case-control study with eight matched controls per case.

Setting-Regions of Ontario, Canada, with an operating nuclear facility.

Subjects-Cases were children (age 0-14) who died from or were diagnosed as having leukaemia from 1950 to 1988 and were born to mothers living in the vicinity of an operating nuclear facility. Controls were identified from birth certificates, matched by date of birth and residence at birth. There were 112 cases and 890 controls.
\end{abstract}

Main outcome measures-Paternal radiation exposure was determined by a record linkage to the Canadian National Dose Registry.

Results-Six fathers of cases and 53 fathers of controls had had a total whole body dose $>0.0$ $\mathrm{mSv}$ before the child's conception, resulting in an odds ratio of $0.87(95 \%$ confidence interval 0.32 to $2 \cdot 34$ ). There was no evidence of an increased leukaemia risk in relation to any exposure period (lifetime or six months or three months before conception) or exposure type (total whole body dose, external whole body dose, or tritium dose), except for radon exposure to uranium miners, which had a large odds ratio that was not significantly different from the null value.

Conclusions-The findings of this study in Ontario did not support the hypothesis that childhood leukaemia is associated with the occupational exposure of fathers to ionising radiation before the child's conception.

Department of Health Care and Epidemiology, University of British Columbia, Vancouver, British Columbia, Canada V6M $1 \mathrm{~K} 6$

Terence W Anderson, professor

Bureau of Radiation and Medical Devices, Department of National Health and Welfare, Ottawa, Ontario, Canada K1A 1C1

J Patrick Ashmore, head, National Dose Registry

Correspondence to: Dr J R McLaughlin, NCIC Epidemiology Unit, Faculty of Medicine, McMurrich

Building, University of

Toronto, Toronto, Ontario, Canada M5S 1A8.

BMF 1993;307:959-66 or a dose of $10 \mathrm{mSv}$ or greater during the six months before conception (the increase in the six month period was revised to sevenfold in a subsequent report ${ }^{6}$ ). Although Gardner et al included cases of both leukaeradiation exposures was seen primarily with childhood leukaemia. As a possible explanation for the paternal radiation effect, Gardner et al speculated that ionising radiation caused a mutation in a father's sperm that could be leukaemogenic in offspring. Other possible explanations were offered, including that the fathers who received a high external whole body radiation dose may also have received workplace exposure to other factors, such as chemicals used in the reprocessing of nuclear fuel and internal sources of ionising radiation (plutonium or tritium). ${ }^{5}$

An association between childhood leukaemia and paternal radiation exposure has not been reported elsewhere; however, only a few studies have directly examined this issue. Leukaemia rates have not been raised among the children of atomic bomb survivors, ${ }^{7-9}$ although it has been suggested that such a discrepancy could arise because of the different rates at which radiation doses were received by atomic bomb survivors and Sellafield workers ${ }^{5}$ and that there may have been differences in the length of time between exposure and conception. Several subsequent casecontrol studies reported from other centres in the United Kingdom were unable to confirm the hypothesis that paternal preconceptional exposure to ionising radiation was associated with childhood leukaemia. ${ }^{10-15}$

In Ontario, Canada's most highly populated province ( $9 \cdot 1$ million people, 1986 census), there are five major nuclear facilities involved in four general types of processes: a research and development facility; a uranium mining and milling facility; a uranium refinery; and two nuclear generating stations. Three of the five facilities are located in regions with very low population densities. A previous ecological study found that the occurrence of childhood leukaemia in the vicinity of these facilities was slightly but not significantly greater than expected. ${ }^{16}$ Radiation doses received by workers in these and other workplaces across Canada are available from the National Dose Registry, a centralised system containing radiation dose records for all monitored workers in Canada dating back to $1951 .{ }^{17}$ Canada differs from the United Kingdom in that it has no facilities for reprocessing nuclear fuel and that certain reactor workers are exposed to tritium, which gives rise to an internal radiation dose. ${ }^{18}$

This case-control study was conducted in Ontario to examine whether there was an association between the occurrence of childhood leukaemia and the cumulative occupational exposure of fathers to ionising radiation before the time of conception, as was reported by Gardner et al..$^{5}$ The study focused on radiation exposures received during employment in the nuclear industry in Ontario. mia and lymphoma, the association with paternal

\section{Methods}

CASE SELECTION AND DESCRIPTION

Cases were children in Ontario, aged 0-14 years, who died from leukaemia during $1950-63$ or were diagnosed 
as having leukaemia during $1964-88$, and were born to mothers who lived near an operating nuclear facility in Ontario at the time of the child's birth. Leukaemia was defined according to the ninth revision of the International Classification of Diseases (ICD-9; classes 204 to 208).$^{19}$ Leukaemia deaths were used as a proxy for leukaemia incidence for the period before 1964, which marks the beginning of incidence data in the Ontario Cancer Registry.

Birth certificates were reviewed to determine the identity (names and date and place of birth) and address of parents. From 1950 to 1963, 778 childhood leukaemia deaths were identified from the Ontario Cancer Registry, for which 762 (98\%) birth certificates were found. Of the 2577 children diagnosed as having leukaemia between 1964 and 1988, birth certificates were found for $2507(97 \%)$.

Cases and controls were selected from regions of the province that contained an operating nuclear facility. The five major facilities were an atomic energy research and development facility at Chalk River, which opened in 1944; a uranium refinery at Port Hope, which opened in 1935; uranium mining and milling facilities at Elliot Lake, which have operated since 1954; a nuclear power station in Bruce County, which opened in 1967; and a nuclear power generating station at Pickering, which started operation in 1971. In the vicinity of the Chalk River research and development facility there was also a small nuclear power station at Rolphton which served as a demonstration project from 1962 to 1987 . The region that was selected around each facility included contiguous postal code areas in which at least $0.5 \%$ of the labour force ${ }^{20}$ was employed at the facility; some areas were as far as $75 \mathrm{~km}$ from a facility. Labour force data were not available for the Elliot Lake and Port Hope facilities; therefore, regions within $25 \mathrm{~km}$ of these facilities were applied in the same way as in the previous ecological study. ${ }^{16}$ Where boundaries overlapped, as occurred for the Pickering and Port Hope facilities and for the Chalk River and Rolphton facilities, the regions were combined. Subjects were thus selected from four distinct regions of the province.

The case series included 112 children. A review of available diagnostic information by a physician and an oncologic pathologist resulted in confirmation of 97 diagnoses $(87 \%)$ by pathology reports, and two diagnoses $(2 \%)$ on the basis of other hospital or clinic records. One case was classified as a "possible" leukaemia on the basis of the pathology report. For the remaining 12 cases, seven of which were based only on a death certificate before 1964 , the diagnosis could not be confirmed because additional information was not available from source hospitals.

Ninety four cases $(84 \%)$ had a form of acute leukaemia, of which 70 were lymphocytic, 14 were myelocytic, and 10 were of another type (table 1 ). Table I also shows that more of these subjects were boys than girls $(60 \% v 40 \%)$ and that $70 \%$ of the cases were aged under 5 years at the time of diagnosis or death, which is typical of the known age and sex specific patterns of leukaemia incidence. ${ }^{21-23}$ The number of cases in individual regions varied according to the total size of the population, with the majority residing in the region that contained the Pickering and Port Hope facilities. Similarly, as a result of the increases in the populations in the regions covered by this study, case frequencies were greater in the more recent years, with $50 \%$ of the case series arising from 1980 to 1988 .

\section{SELECTION OF CONTROLS}

Birth certificates were used to identify control children, matched to a case according to date of birth (within three months) and the region in which the
TABLE I-Type of leukaemia, region, sex, age, and year of diagnosis or death in 112 cases of childhood leukaemia

\begin{tabular}{lc}
\hline & $\begin{array}{c}\text { No (\%) } \\
\text { of cases }\end{array}$ \\
\hline Type of leukaemia: & \\
Acute lymphocytic (ICD-9 204.0) & $70(63)$ \\
Acute myelocytic (ICD-9 205.0) & $14(13)$ \\
Other acute leukaemia (ICD-9 206.0, 207.0, 208.0) & $10(9)$ \\
Chronic leukaemia (ICD-9 205.1) & $4(3)$ \\
Other (ICD-9 207.2, 207.8, 208.8, 208.9) & $14(13)$ \\
Sex: & \\
Female & $45(40)$ \\
Male & $67(60)$ \\
Age at diagnosis or death (years): & \\
$0-4$ & $79(71)$ \\
$5-9$ & $22(20)$ \\
10-14 & $11(9)$ \\
Region: & \\
Nuclear generating station (Pickering) & \\
and uranium refinery (Port Hope) & $69(62)$ \\
Nuclear generating station (Bruce) & $21(19)$ \\
Research and development (Chalk River) & $17(15)$ \\
Uranium mines and mill (Elliot Lake) & $5(4)$ \\
Year of diagnosis or death: & $6(5)$ \\
1950-9 & $15(13)$ \\
1960-9 & $35(31)$ \\
$1970-9$ & $56(50)$ \\
$1980-8$ & \\
\hline ICD-9=ninth revision, International Classification of Diseases. &
\end{tabular}

mother lived at the time of the child's birth. Eight controls were selected for each case to enhance the power of the study, so that 896 potential controls were initially identified as the comparison group for the 112 eligible cases. Six control children were excluded because they died before the date of their associated case's diagnosis, resulting in a control series of 890 children.

\section{RECORD LINKAGE TO NATIONAL DOSE REGISTRY}

Occupational radiation exposure data pertaining to the fathers of cases and controls were obtained by conducting a linkage with the National Dose Registry. A computerised record linkage was performed, whereby potential links were weighted according to the degree of agreement of the phonetic version of the surname and of the given names, birth date, and sex. Staff at the registry involved in the linkage were not aware whether the men being linked were fathers of cases or controls.

The major focus of this study was nuclear workers, defined as those who worked at any stage of the nuclear fuel cycle in Ontario (mining, milling, and refining of uranium; production of fuel rods; or development, construction, operation, and maintenance of nuclear reactors) and who had a detectable $(>0 \mathrm{mSv})$ cumulative lifetime radiation dose. To maximise the certainty with which links were made, it was necessary to contact employers to obtain identifying information that was missing in the National Dose Registry. This was feasible for nuclear workers because they were employed at a small number of large organisations. For potential links of non-nuclear workers, efforts to obtain additional identifying information were limited to a search of historical files maintained by the National Dose Registry.

A link was obtained for $9.5 \%(95 / 1002)$ of the individuals in the study, with 91 classified as definite links and four classified as probable links. On the basis of the most recent occupational category for the 95 individuals who were identified in the National Dose Registry, there were 52 reactor workers, 31 uranium miners, 10 workers in other industries, one medical worker, and one for whom the job class was not available.

\section{RADIATION EXPOSURE DATA}

The data obtained from the National Dose Registry for every linked individual consisted of occupation, job location, and a complete lifetime dose history, including doses arising in any province. Where pos- 
sible, doses were verified by comparing reported values with employer records.

Radiation exposures considered in this study were whole body external dose, whole body tritium dose, and radon daughter exposure. The external whole body dose was recorded by film or thermoluminescent dosimeters and included doses from $\gamma$ radiation, high energy $\beta$ radiation, and $x$ rays. Tritium, which is the most common type of internal exposure for workers at Canadian facilities with nuclear reactors, was measured as a concentration in urine and converted to a dose equivalent expressed in $\mathrm{mSv}$. For convenience in this report, dose and dose equivalent are assumed to have the same meaning and are used interchangeably. The exposure of uranium miners to radon progeny was in most instances estimated from work area measurements and occupancy factors (job type and duration) and recorded in working level months. In this report, radon is used to refer to both radon gas and radon progeny.

Separate analyses were undertaken for whole body external dose, whole body tritium dose, and total whole body dose (external plus tritium), as well as for radon exposures. Radon exposures are not available as effective dose equivalents in the National Dose Registry and were therefore not added to the total whole body dose.

Lifetime and annual radiation doses were obtained from the National Dose Registry. Dose calculations were made for the most critical periods that were identified by Gardner et al-namely, the lifetime cumulative exposure ending at the time of conception (estimated by birth date minus 270 days) and the cumulative exposure over the six months before a child's conception. ${ }^{45}$ Radiation dose was also estimated for the three months before a child's conception because this period relates more closely to the length of the spermatogenic cycle. ${ }^{24}$

Dose data were obtained in as much detail as possible from the National Dose Registry and from employers for the three year period ending in the year of a child's birth. This included the collection of individual dose measurements made on the basis of dosimetric badge readings for external dose and urine analysis for tritium exposure. The availability of these measurements, many of which had been made at biweekly intervals, enabled the accurate calculation of dose for the specific period of interest and permitted an evaluation of the quality of the data reported by the National Dose Registry. For two nuclear workers, detailed data were not available; therefore, doses for the six months and three months before conception were estimated on the basis of the annual doses contained in the National Dose Registry. Uranium miners in Ontario were not monitored before 1981 for $\gamma$ exposures or before 1968 for radon exposures; therefore, for these periods external whole body and radon exposures were estimated on the basis of work history (job type, location, duration) and mine charac-

TABLE I-Number of cases and controls and odds ratios for leukaemia in children by linkage status and general occupational class of father

\begin{tabular}{|c|c|c|c|c|c|}
\hline Factor & $\begin{array}{c}\text { Cases } \\
(n=112)\end{array}$ & $\begin{array}{l}\text { Controls } \\
(n=890)\end{array}$ & $\begin{array}{l}\text { Odds ratios }(95 \% \\
\text { confidence } \\
\text { interval) }\end{array}$ & $\begin{array}{l}\text { Likelihood ratio } \\
\text { test (degrees of } \\
\text { freedom) }\end{array}$ & $\mathrm{p}$ Value \\
\hline \multicolumn{6}{|c|}{ Linked to National Dose Registry: } \\
\hline $\begin{array}{l}\text { No (never exposed) } \\
\text { Yes }\end{array}$ & 101 & $\begin{array}{r}806 \\
84\end{array}$ & 1.00 & \multirow[t]{2}{*}{$0.03(1)$} & 0.86 \\
\hline \multicolumn{5}{|l|}{ Employed in nuclear industry: } & \\
\hline Never exposed & 101 & 806 & 1.00 & \multirow{4}{*}{$0.60(2)$} & \multirow{3}{*}{0.74} \\
\hline Non-nuclear worker & 1 & 3 & $2.67(0.28$ to 25.6$)$ & & \\
\hline Nuclear worker & 10 & 81 & $0.99(0.45$ to 2.19$)$ & & \\
\hline \multicolumn{5}{|l|}{ Job class: } & \\
\hline Never exposed & 101 & 806 & 1.00 & \multirow{5}{*}{$3.96(3)$} & \multirow{5}{*}{0.27} \\
\hline Reactor worker & 4 & 48 & $0.64(0.22$ to 1.86$)$ & & \\
\hline Uranium miner & 5 & 26 & $7.27(0.59$ to 88.7$)$ & & \\
\hline \multirow{2}{*}{$\begin{array}{l}\text { Other job class (industrial, } \\
\text { medical, unknown) }\end{array}$} & & & & & \\
\hline & 2 & 10 & $1.59(0.34$ to 7.44$)$ & & \\
\hline
\end{tabular}

teristics, using procedures developed in a previous cohort study of miners. ${ }^{25}$

\section{COVARIABLES}

Covariable information was limited to that available on birth certificates, including maternal age, birth weight, birth order, and sex. The other available covariable was the distance between a child's residence at birth (estimated by the centre of the census subdivision) and the nearest nuclear facility. Three categories of the distance variable were defined $(0-14 \mathrm{~km}$, $15-29 \mathrm{~km}, \geqslant 30 \mathrm{~km}$ ). The covariables were analysed individually to determine whether they were associated with the occurrence of childhood leukaemia, and as potential confounders of the primary relationship under study.

\section{STATISTICAL METHODS}

The relative risk of developing leukaemia for each covariable level was estimated as an odds ratio and presented with $95 \%$ confidence intervals. Significance testing was performed with likelihood ratio tests and a two tailed $\alpha$ probability of 0.05 . Analyses were performed with conditional multivariable logistic regression analysis in EGRET. ${ }^{26}$ For ordinal variables with more than two categories, a likelihood ratio test with one degree of freedom was performed as a trend test to determine whether there was a linear component of trend in risk across the multiple categories. When none of the cases contributed to the estimation of an odds ratio for a particular dose category, exact analyses were performed to estimate conditional score test statistics and the upper confidence limit of the odds ratio with LogXact. ${ }^{27}$ Continuous variables were categorised on the basis of the control distributions (quartiles) or categories of radiation dose that were reported in previous studies (Gardner et $a t^{45}$ ). Subgroup analyses were performed to examine whether there was variation in the odds ratios for radiation exposures across strata defined by the specific type of leukaemia and the matching variables (age, period of time, region of the province). To permit a comparison between results of this study and those of Gardner $e t a \bar{p}$ the exact conditional probability of obtaining the observed data under the assumption that the previously reported odds ratio was the true value was calculated as the product of exact probabilities ${ }^{28}$ for each case-control risk set.

Further details of all study procedures are presented in a previously published technical report. ${ }^{29}$

\section{Results}

The linkage to the National Dose Registry resulted in the identification of fathers of 11 cases and 84 controls, who were monitored for occupational exposure to radiation, giving an odds ratio of 1.07 , which was not significantly different from the null value of 1.0 ( $95 \%$ confidence interval 0.50 to 2.29 ) (table II). The majority of fathers who linked to the National Dose Registry were employed in the nuclear industry, with fathers of 10 cases and 81 controls being nuclear workers. Relative to the individuals who had never been exposed to radiation in the workplace, offspring of nuclear workers had the same risk (odds ratio 0.99), whereas for the small number of nonnuclear workers (one case and three controls) the odds ratio was 2.67 , with a very wide confidence interval $(0.28$ to $25 \cdot 6)$ that encompassed the null value.

Analyses by occupation indicated that for reactor workers, who constituted the majority of nuclear workers, there was a lower than expected risk of leukaemia among children $(0.64 ; 0.22$ to 1.86$)$, whereas workers in other industrial, medical, or unknown fields had an odds ratio of $1.59(0.34$ to $7 \cdot 44)$. 
For uranium miners the odds ratio was $7 \cdot 27$ with a very .wide confidence interval $(0.59$ to 88.7$)$. The likelihood ratio test indicated that the variation in odds ratios between the paternal occupational classes was not statistically significant $(3 \cdot 96, \mathrm{df}=3, \mathrm{p}=0 \cdot 27)$.

The number of fathers with a detectable radiation exposure $(>0.0 \mathrm{mSv}$ in table III) is less than that shown in table II because several fathers who were listed in the dose registry received their initial exposures after the child's conception (or diagnosis). Fathers of six cases and 53 controls had a detectable total whole body exposure before conception, giving an odds ratio of 0.87 and a confidence interval that included a value of $1.0(0.32$ to $2 \cdot 34)$. Odds ratios were also close to 1.0 for total whole body exposures during both the six months and three months before conception. Between the times of conception and diagnosis an additional three cases and 11 controls received their first dose, resulting in nine cases and 64 controls with a detectable total whole body dose $(1 \cdot 19 ; 0.51$ to $2 \cdot 73)$.

The equivalence of the frequencies and odds ratio for preconception total whole body dose and external whole body dose (table III) indicated that tritium exposures were very small relative to external exposures. Detectable tritium doses before conception occurred in 14 controls but none of the cases, giving an

TABLE II-Number of cases and controls, and odds ratios for leukaemia in children by type of paternal radiation exposure (any detectable dose)

\begin{tabular}{|c|c|c|c|c|c|}
\hline Paternal exposure & $\begin{array}{c}\text { Cases } \\
(\mathrm{n}=112)\end{array}$ & $\begin{array}{l}\text { Controls } \\
(\mathrm{n}=890)\end{array}$ & $\begin{array}{l}\text { Odds ratios }(95 \% \\
\text { confidence } \\
\text { interval) }\end{array}$ & $\begin{array}{c}\text { Likelihood ratio } \\
\text { test }^{\star}\end{array}$ & p Value \\
\hline \multirow{2}{*}{\multicolumn{6}{|c|}{ Total whole body dose (external plus internal due to tritium) (mSv): }} \\
\hline & & & & & \\
\hline 0.0 & 106 & 837 & 1.00 & \multirow[b]{2}{*}{0.08} & \multirow[b]{2}{*}{$0 \cdot 78$} \\
\hline$\geqslant 0.1$ & 6 & 53 & $0.87(0.32$ to 2.34$)\}$ & & \\
\hline \multicolumn{6}{|c|}{ During 6 months before conception: } \\
\hline 0.0 & 107 & 849 & $1 \cdot 00$ & & \multirow{2}{*}{0.95} \\
\hline$\geqslant 0.1$ & 5 & 41 & $0.96(0.34$ to 2.77$)\}$ & 0 & \\
\hline \multicolumn{6}{|c|}{ During 3 months before conception: } \\
\hline 0.0 & 107 & 849 & 1.00 & \multirow{2}{*}{0} & \multirow{2}{*}{0.95} \\
\hline$\geqslant 0.1$ & 5 & 41 & $0.96(0.34$ to 2.77$)$ & & \\
\hline \multicolumn{6}{|l|}{ Before diagnosis: } \\
\hline $0 \cdot 0$ & 103 & 826 & 1.00 & \multirow{2}{*}{$0 \cdot 15$} & \multirow{2}{*}{$0 \cdot 70$} \\
\hline$\geqslant 0 \cdot 1$ & 9 & 64 & $1.19(0.51$ to 2.73$)\}$ & & \\
\hline \multicolumn{6}{|c|}{ External whole body dose before conception $(\mathrm{mSv})$ : } \\
\hline 0.0 & 106 & 837 & 1.00 & \multirow{2}{*}{0.08} & \multirow[b]{2}{*}{$0 \cdot 78$} \\
\hline$\geqslant 0 \cdot 1$ & 6 & 53 & $0.87(0.32$ to 2.34$)\}$ & & \\
\hline \multicolumn{6}{|c|}{ Tritium dose (internal whole body) before conception (mSv): } \\
\hline 0.0 & 112 & 876 & 1.00 & \multirow{4}{*}{$1 \cdot 80+$} & \multirow{3}{*}{$0 \cdot 25$} \\
\hline$\geqslant 0.1$ & 0 & 14 & 0.00 (0 to 2.39$)$ & & \\
\hline \multirow{2}{*}{\multicolumn{5}{|c|}{$\begin{array}{l}\text { Radon dose (internal dose to lung) (working level months): } \\
\text { Before conception: }\end{array}$}} & \\
\hline & & & & & \\
\hline $\begin{array}{l}0.0 \\
\geq 0.1\end{array}$ & 108 & 868 & 1.00 & \multirow{2}{*}{$1 \cdot 12$} & \multirow{2}{*}{$0 \cdot 29$} \\
\hline During 6 months before conception: & 4 & 22 & $2.80(0.39$ to 20.0$)\}$ & & \\
\hline 0.0 & 108 & 873 & 1.00 & \multirow{2}{*}{2.54} & \multirow{2}{*}{0.11} \\
\hline$\geqslant 0 \cdot 1$ & 4 & 17 & $5.17(0.53$ to 50.1$)\}$ & & \\
\hline
\end{tabular}

TABLE IV-Number of cases and controls and odds ratios for leukaemia in children by type and level of paternal radiation exposure

\begin{tabular}{|c|c|c|c|c|c|}
\hline Paternal exposure & $\begin{array}{c}\text { Cases } \\
(n=112)\end{array}$ & $\begin{array}{l}\text { Controls } \\
(n=890)\end{array}$ & $\begin{array}{l}\text { Odds ratios }(95 \% \\
\text { confidence } \\
\text { interval) }\end{array}$ & $\begin{array}{l}\text { Likelihood ratio } \\
\text { test (degrees of } \\
\text { freedom) }\end{array}$ & p Value \\
\hline \multicolumn{6}{|c|}{ Total whole body dose (external plus internal due to tritium) (mSv): } \\
\hline \multicolumn{6}{|c|}{ Before conception: } \\
\hline 0 & 106 & 837 & 1.00 & \multirow{3}{*}{$0 \cdot 19(2)$} & \multirow{3}{*}{0.91} \\
\hline $0 \cdot 1-1 \cdot 49$ & 4 & 39 & $0.80(0.26$ to 2.47$)$ & & \\
\hline$\geqslant 50$ & 2 & 14 & $1.09(0.21$ to 5.55$)$ & & \\
\hline \multicolumn{6}{|c|}{ During 6 months before conception: } \\
\hline 0 & 107 & 849 & 1.00 & \multirow{3}{*}{$0 \cdot 32(2)$} & \multirow{3}{*}{0.85} \\
\hline $0 \cdot 1-4 \cdot 9$ & 2 & 22 & 0.73 (0.16 to 3.31$)$ & & \\
\hline$\geqslant 5$ & 3 & 19 & $1.25(0.32$ to 4.75$)$ & & \\
\hline \multicolumn{6}{|l|}{ Before diagnosis: } \\
\hline 0 & 103 & 826 & 1.00 & \multirow{4}{*}{$0.79(3)$} & \multirow{4}{*}{0.85} \\
\hline $0 \cdot 1-49$ & 6 & 39 & $1.27(0.49$ to 3.32$)$ & & \\
\hline $50-59$ & 1 & 14 & $0.62(0.07$ to 5.00$)$ & & \\
\hline$\geqslant 100$ & 2 & 11 & $1.57(0.26$ to 9.60$)$ & & \\
\hline \multicolumn{6}{|c|}{ External whole body dose before conception $(\mathrm{mSv})$ : } \\
\hline 0 & 106 & 837 & 1.00 & \multirow{3}{*}{$0 \cdot 37(2)$} & \multirow{3}{*}{0.83} \\
\hline $0 \cdot 1-49$ & 4 & 41 & $0.77(0.25$ to 2.36$)$ & & \\
\hline$\geqslant 50$ & 2 & 12 & $1.29(0.23$ to 7.00$)$ & & \\
\hline \multicolumn{6}{|c|}{ Radon dose (internal dose to lung) before conception (working level months): } \\
\hline 0 & 108 & 868 & 1.00 & \multirow{3}{*}{$\begin{array}{l}1.86(2) \\
1.83(1)^{\star}\end{array}$} & \multirow{3}{*}{$\begin{array}{l}0.39 \\
0.18\end{array}$} \\
\hline $0 \cdot 1-49$ & 2 & 16 & $1.89(0.21$ to 17.3$)$ & & \\
\hline$\geqslant 50$ & 2 & 6 & $5.14(0.48$ to 55.2$)$ & & \\
\hline
\end{tabular}

odds ratio that was less than but not significantly (rom $1.0(p=0.25$ exact test). Preconception radon exposures from uranium mining occurred for thers of four cases and 22 controls, resulting in an odds ratio of $2 \cdot 80$ and a very wide confidence interval $(0.39$ to 20.0$)$; radon exposures in the six months before conception had a large but imprecise odds ratio $(5 \cdot 17 ; 0.53$ to $50 \cdot 1)$.

In an assessment of whether risk varied with total whole body dose, lifetime preconception dose was categorised into three classes, with $0.0 \mathrm{mSv}$ as the baseline, giving odds ratios of 0.80 for $0.1-1.49 \mathrm{mSv}$ and 1.09 for $50 \mathrm{mSv}$ or greater (table IV). The likelihood ratio statistic $(0.19)$ on two degrees of freedom indicated that the variation in odds ratios across the three dose categories was not significant $(p=0.91)$. Further analyses showed that paternal lifetime preconception doses of $\geqslant 100 \mathrm{mSv}$ occurred in five controls but did not occur among cases (not presented in table IV). Owing to the small frequencies and the absence of such paternal exposure among cases, the results were pooled for doses of $\geqslant 50 \mathrm{mSv}$. During the six months before conception the odds ratios for total whole body doses of $1-4 \mathrm{mSv}$ and $\geqslant 5 \mathrm{mSv}$ were 0.73 and $1 \cdot 25$, respectively (table IV). Further analyses of higher doses during this six month period showed that seven controls but none of the cases had doses of $\geqslant 10 \mathrm{mSv}$. In the three months before conception, fathers of eight controls but none of the cases had doses of $\geqslant 5 \mathrm{mSv}$; therefore, analyses of doseresponse could not be performed for this exposure period. Exposures were slightly higher for both cases and controls when considered up to the time of diagnosis, with fathers of two cases and 11 controls having doses of $\geqslant 100 \mathrm{mSv}$ (table IV). There was no significant variation in the odds ratios, which were $1.27,0.62$, and 1.57 for the prediagnosis dose categories of $0 \cdot 1-49,50-99$, and $\geqslant 100 \mathrm{mSv}$.

Preconception radon exposures of 0.1-49 and $\geqslant 50$ working level months had odds ratios of $1.89(0.21$ to $17 \cdot 3)$ and $5 \cdot 14(0 \cdot 48$ to $55 \cdot 2)$, respectively, with the latter being based on two exposed cases and six exposed controls (table IV). Although the odds ratio increased with increasing radon level, the estimates were statistically imprecise and a significant trend was not detected. Uranium miners constituted a relatively large proportion of those in the highest category ( $\geqslant 50 \mathrm{mSv}$ ) of total whole body dose before conception: the fathers of both cases and seven of the 14 fathers of controls were uranium miners.

Table $\mathrm{V}$ presents results of univariable analyses of the potentially confounding factors. There was no significant variation between categories of maternal age, although there was a statistically significant trend in risk. No significant variation in risk was detected across categories of birth weight or birth order. Boys had a risk of leukaemia that was 1.45 -fold greater than that of girls $(p=0.07)$. Distance between a child's residence at birth and the nearest nuclear facility was not significantly associated with risk. Overall, this distance was similar for cases (mean 25.6 ( $\mathrm{SE}=0.6$ ) $\mathrm{km}$ ) and controls (mean $24.3(1 \cdot 7) \mathrm{km}$ ), although it varied among the four areas, with a mean distance of $8 \mathrm{~km}$ in the region of the Elliot Lake uranium mines, $16 \mathrm{~km}$ in the region of the Pickering power station and the Port Hope uranium refinery, $35 \mathrm{~km}$ in the region of the Chalk River research and development facility, and $45 \mathrm{~km}$ in the region of the Bruce County power station.

The question of whether there was confounding by covariables was assessed for subjects who had complete data $(n=936)$ by comparing crude odds ratios with adjusted odds ratios from multivariable models (table VI). For total whole body dose before conception the adjusted odds $(1.06)$ ratio was slightly greater than the crude odds ratio $(1 \cdot 00)$. The potential confounders also 
TABLE V-Number of cases and controls, and odds ratios for leukaemia in children by maternal age, birth characteristics, sex, and distance from a nuclear facility

\begin{tabular}{|c|c|c|c|c|c|}
\hline Risk factor & $\begin{array}{c}\text { Cases } \\
(\mathrm{n}=112)\end{array}$ & $\begin{array}{l}\text { Controls } \\
(\mathrm{n}=890)\end{array}$ & $\begin{array}{l}\text { Odds ratios }(95 \% \\
\text { confidence } \\
\text { interval) }\end{array}$ & $\begin{array}{l}\text { Likelihood ratio } \\
\text { test (degrees of } \\
\text { freedom) }\end{array}$ & $\mathrm{p}$ Value \\
\hline \multicolumn{6}{|c|}{ Mother's age (years): } \\
\hline $15-22$ & 35 & 219 & 1.00 & \multirow{4}{*}{$\begin{array}{l}4 \cdot 02(3) \\
3 \cdot 84(1)^{\star}\end{array}$} & \\
\hline $23-26$ & 36 & 262 & $0.85(0.50$ to 1.41$)$ & & 0.26 \\
\hline $27-29$ & 19 & 186 & $0.64(0.35$ to 1.16$)$ & & 0.05 \\
\hline$\geqslant 30$ & 22 & 223 & $0.61(0.34$ to 1.08$)$ & & \\
\hline \multicolumn{6}{|c|}{ Child's birth weight (g): } \\
\hline$<3001$ & 16 & 166 & 1.00 & \multirow{4}{*}{$6 \cdot 38(3)$} & \multirow{4}{*}{$0 \cdot 10$} \\
\hline $3001-3400$ & 34 & 244 & $1.44(0.78$ to 2.67$)$ & & \\
\hline $3401-3685$ & 35 & 205 & $1.76(0.95$ to 3.29$)$ & & \\
\hline$>3685$ & 19 & 217 & $0.92(0.46$ to 1.83$)$ & & \\
\hline \multicolumn{6}{|c|}{ Child's birth order: } \\
\hline 1 & 43 & 315 & 1.00 & \multirow{4}{*}{$\begin{array}{l}0.58(3) \\
0.44(1)^{\star}\end{array}$} & \multirow{4}{*}{$\begin{array}{l}0.90 \\
0.51\end{array}$} \\
\hline 2 & 36 & 300 & $0.87(0.54$ to 1.40$)$ & & \\
\hline 3 & 17 & 144 & $0.83(0.46$ to 1.51$)$ & & \\
\hline$\geqslant 4$ & 14 & 115 & $0.84(0.42$ to 1.65$)$ & & \\
\hline \multicolumn{6}{|l|}{ Sex: } \\
\hline Female & 45 & 439 & 1.00 & \multirow{2}{*}{$3 \cdot 32(1)$} & \multirow{2}{*}{0.07} \\
\hline Male & 67 & 451 & $1.45(0.97$ to 2.15$)$ & & \\
\hline \multicolumn{6}{|c|}{ Distance from nuclear facility $(\mathrm{km})$ : } \\
\hline $0-14$ & 46 & 370 & 1.00 & \multirow{3}{*}{$0 \cdot 36(2)$} & \multirow{3}{*}{0.83} \\
\hline $15-29$ & 27 & 227 & $0.96(0.44$ to 2.11$)$ & & \\
\hline$\geqslant 30$ & 39 & 293 & $1.17(0.55$ to 2.49$)$ & & \\
\hline
\end{tabular}

${ }^{\star}$ Test for linear trend.

TABLE VI-Comparison of crude and adjusted odds ratios (adjusted for maternal age, birth weight, sex, and distance in a multivariable logistic regression model) for preconception total whole body dose and radon exposure

\begin{tabular}{|c|c|c|}
\hline Paternal exposure & $\begin{array}{l}\text { Adjusted odds ratio } \\
\text { (95\% confidence } \\
\text { interval })^{\star}\end{array}$ & $\begin{array}{l}\text { Crude odds ratio } \\
(95 \% \text { confidence } \\
\text { interval })^{\star}\end{array}$ \\
\hline \multicolumn{3}{|c|}{ Total whole body dose (external plus tritium) (mSv): } \\
\hline 0 & 1.00 & 1.00 \\
\hline$\geqslant 0 \cdot 1$ & $1.06(0.36$ to $3 \cdot 10)$ & $1.00(0.36$ to 2.76$)$ \\
\hline \multicolumn{3}{|c|}{ Radon exposure (internal lung dose) (working level months): } \\
\hline 0 & 1.00 & 1.00 \\
\hline$\geqslant 0.1$ & $2.54(0.33$ to 19.4$)$ & $2.80(0.39$ to 20.00$)$ \\
\hline
\end{tabular}

TABLE VII-Number of cases and controls, and odds ratios for leukaemia in children for father's total whole body radiation exposures before child's conception, stratified by region, age, period of diagnosis, and type of leukaemia

\begin{tabular}{|c|c|c|c|c|}
\hline Stratum & Dose (mSv) & Cases & Controls & $\begin{array}{c}\text { Odds ratio } \\
\text { (95\% confidence } \\
\text { interval) }\end{array}$ \\
\hline \multicolumn{5}{|l|}{ Region: } \\
\hline Power station and refinery $(n=616)$ & $\begin{array}{c}0 \\
\geqslant 0 \cdot 1\end{array}$ & $\begin{array}{r}68 \\
1\end{array}$ & $\begin{array}{r}538 \\
9\end{array}$ & $\begin{array}{l}1.00 \\
0.87(0.11 \text { to } 7.06)\end{array}$ \\
\hline \multirow[t]{2}{*}{ Power station $(n=190)$} & 0 & 20 & 161 & 1.00 \\
\hline & $\geqslant 0.1$ & 1 & 9 & $1.00(0.11$ to 9.07$)$ \\
\hline \multirow[t]{2}{*}{ Research and development $(n=151)$} & 0 & 17 & 119 & 1.00 \\
\hline & $\geqslant 0.1$ & 0 & 15 & $0.00(0.2 \text { to } 2.23)^{\star}$ \\
\hline \multirow[t]{2}{*}{ Uranium mine and mill $(n=45)$} & 0 & 1 & 19 & 1.00 \\
\hline & $\geqslant 0.1$ & 4 & 21 & $3.96(0.38$ to 41.8$)$ \\
\hline \multicolumn{5}{|l|}{ Age at diagnosis (or death): } \\
\hline $0-4$ years $(n=705)$ & $\begin{array}{c}0 \\
\geqslant 0 \cdot 1\end{array}$ & $\begin{array}{r}75 \\
4\end{array}$ & $\begin{array}{r}595 \\
31\end{array}$ & $\begin{array}{l}1.00 \\
1.03(0.33 \text { to } 3.25)\end{array}$ \\
\hline \multirow[t]{2}{*}{$5-14$ years $(n=297)$} & 0 & 31 & 242 & 1.00 \\
\hline & $\geqslant 0.1$ & 2 & 22 & $0.57(0.09$ to 3.67$)$ \\
\hline \multirow{2}{*}{$\begin{array}{l}\text { Period of diagnosis (or death): } \\
\quad 1950-69(\mathrm{n}=187)\end{array}$} & & & & \\
\hline & $\begin{array}{c}0 \\
\geqslant 0.1\end{array}$ & $\begin{array}{r}19 \\
2\end{array}$ & $\begin{array}{r}148 \\
18\end{array}$ & $\begin{array}{l}1.00 \\
0.85(0.15 \text { to } 4.80)\end{array}$ \\
\hline $1970-9(n=314)$ & $\begin{array}{l}0 \\
\geqslant 0 \cdot 1\end{array}$ & 33 & 264 & $\begin{array}{l}1.00 \\
1.13(0.12 \text { to } 10.32)\end{array}$ \\
\hline $1980-8(n=501)$ & $\begin{array}{c}0 \\
0 \\
\geqslant 0.1\end{array}$ & $\begin{array}{r}54 \\
2\end{array}$ & $\begin{array}{r}425 \\
20\end{array}$ & $\begin{array}{l}1.13(0.12 \text { to } 10.32) \\
1.00 \\
0.79(0.18 \text { to } 3.52)\end{array}$ \\
\hline \multicolumn{5}{|l|}{ Type of leukaemia: } \\
\hline Acute lymphocytic $(n=70)$ & $\begin{array}{c}0 \\
\geqslant 0.1\end{array}$ & $\begin{array}{r}66 \\
4\end{array}$ & $\begin{array}{r}530 \\
26\end{array}$ & $\begin{array}{l}1.00 \\
1.35(0.38 \text { to } 4.83)\end{array}$ \\
\hline All others $(n=42)$ & $\begin{array}{l}0 \\
\geqslant 0.1\end{array}$ & $\begin{array}{r}40 \\
2\end{array}$ & $\begin{array}{r}307 \\
27\end{array}$ & $\begin{array}{l}1.00 \\
0.51(0.10 \text { to } 2.51)\end{array}$ \\
\hline
\end{tabular}

«Exact analysis.

had only a slight effect on the less precise odds ratios for preconception radon exposures, with the adjusted odds ratio $(2 \cdot 54)$ being closer to the null value than the crude odds ratio $(2 \cdot 80)$. Overall, there was no evidence of serious confounding by the covariables that were available.

Stratified analyses were performed to determine whether risk varied according to region (table VII). This showed that the majority of subjects $(n=616)$ arose from the heavily populated area with a nuclear power station (Pickering) and uranium refinery (Port Hope), and that the region with the uranium mines and mill (Elliot Lake) contributed few subjects $(n=45)$. In contrast, a large proportion of the subjects whose fathers had a detectable preconception radiation dose arose from the uranium mining areas ( 4 of 5 cases, 21 of 40 controls). In the region of the power station and refinery, the fathers of one case and nine controls had a detectable preconception total whole body dose, and of these the exposures arose in the uranium refinery for the single case and for two controls. Odds ratios for detectable total whole body doses were less than or close to 1.0 for all but the uranium mining region, where the odds ratio was $3.96(0.38$ to 41.8$)$. A significant association did not occur in any of the regions.

Stratified analyses were also performed to determine whether risk varied according to age at diagnosis, period of diagnosis, and type of leukaemia (table VII). No significant variation in odds ratios was detected in these strata.

It was possible to evaluate the quality of the dose data obtained from the National Dose Registry for 52 individuals who worked in the nuclear generating stations or the research and development facility. Two values of lifetime external dose and tritium dose before conception were estimated, one based on the National Dose Registry data and one based on the employers' original source files. Fourteen $(27 \%)$ workers had a discrepancy of more than $1.0 \mathrm{mSv}$; however, the difference was large enough to affect the allocated dose category for only one individual, who was a control.

\section{Discussion}

This assessment of whether paternal radiation exposures were leukaemogenic in offspring considered the effects of both external and internal radiation exposures during periods before both conception and diagnosis while fathers were employed in a wide range of occupations. No statistically significant associations were detected between childhood leukaemia and any of these paternal radiation exposures. In particular, there was no evidence of an increased risk in relation to paternal radiation exposures during the lifetime, six months, or three months before conception. In addition to the lack of association with radiation exposures at any detectable level $(>0.0 \mathrm{mSv})$ there was no apparent gradient of effect with increasing radiation dose. Odds ratios obtained for the period before diagnosis were slightly greater than for the preconception period, which is contrary to what would be expected if the preconception period was indeed the most important aetiologically.

Relative risk estimates obtained for total and external whole body doses were similar, largely because external exposures constituted most of the total doses. Gardner et al reported an association with external exposures but also speculated that unknown internal exposures may have contributed to the excess risk. ${ }^{5}$ Internal exposures due to tritium were considered in this study and found not to be associated with excess risk, as only fathers of controls had tritium exposures.

The largest, but also the least stable, relative risk estimates in this study referred to uranium miners and their exposures to radon and radon progeny, with uranium miners having an odds ratio of $7.27(0.59$ to $88.7)$. The results pertaining to uranium miners and radon exposures must be interpreted with caution for several reasons. Firstly, the results are extremely imprecise, as indicated by the wide confidence intervals, because only five cases of childhood leukaemia occurred in the uranium mining and milling region between 1954 and 1988; all the information about uranium mining and radon thus derived from five matched sets of cases and controls. Secondly, uranium miners are potentially exposed to occupational hazards other than radiation and these may be corre- 
lated with the mining and radon variables, but because such underlying factors were not measured their impact could not be directly assessed. Thirdly, although it has been suggested that there may be an association between leukaemia and radon exposures, ${ }^{30}$ it has not previously been suggested that radon could affect offspring. Fourthly, the previous ecological study in Ontario found no excess of childhood leukaemia in the mining region. ${ }^{16}$ Fifthly, even if there was a true leukaemogenic effect in uranium miners, it is probably not attributable to radon gas because the very short half lives of radon and radon progeny result in most of the dose being delivered to the lungs rather than other organs. ${ }^{31}$ Therefore, at this time it is concluded that the large odds ratios for uranium miners and radon exposures have little aetiological significance.

\section{VALIDITY}

The potential effect on validity of the study was considered for many factors. Multivariable analyses showed that the main results were not confounded by the few covariables that were available. Recall bias, which is a concern in many case-control studies, did not compromise validity because the information on radiation exposure was obtained from pre-existing records. Selection bias probably did not occur because cases and controls were identified from a common data source (birth certificates) which was unrelated to the exposure of primary interest. By performing conditional statistical analyses which accounted for the matched nature of the data we controlled the possible confounding by the matching variables. Given that there is regional variation in background radiation exposure, a large part of which is due to ambient radon progeny in non-occupational settings, the matching of cases and controls by region at least partially accounted for this factor, which has been suggested as a risk factor for leukaemia. ${ }^{30}$

The validity of a study can also be threatened if exposure or outcome is measured with error. Several potential sources of measurement error were assessed, including factors related to how radiation dose was detected (use and type of badge dosimeter), calculated (changes in dosimetry models over time), and reported (reporting thresholds; impact of emigration by controls on dose after birth); how and to what degree of certainty links were detected in the National Dose Registry (of 194 men with known status who were included in the linkage, all were correctly classified); and how and to what degree of certainty outcome was detected in the Ontario Cancer Registry (certainty of diagnosis; impact of emigration). Also, cases probably were not missed by the Ontario Cancer Registry, given that the registration of leukaemia at all ages has been estimated to be $95 \%$ complete, and over-reporting of childhood cancers has been identified previously. ${ }^{33}$ Several factors had a trivial effect on the measured radiation doses, and only a few factors caused a slight reallocation of individuals to dose categories. It should be noted that because errors in dose measurement and linkage classification would have affected the fathers of cases and controls equally, odds ratio estimates obtained in this study may have been biased towards the null value; however, given that little misclassification was detected, the potential magnitude of such biases would be very small. Details of the methods and results of the evaluations of potential threats to study validity are presented elsewhere. ${ }^{29}$ In general, sensitivity analyses of the impact of these errors in the dose measurements did not result in a bias that would cause this study to fail to detect a true association between paternal radiation exposure and leukaemia in offspring.

The radiation dose categories that Gardner et al found to be most strongly associated with leukaemia risk around the Sellafield facility-namely, preconception doses $\geqslant 100 \mathrm{mSv}$ or $\geqslant 10 \mathrm{mSv}$ over six monthswere specifically considered. The number of individuals in these relatively high dose categories was small; however, the prevalences of such exposures were only slightly less than those reported by Gardner et al. ${ }^{5}$ We found a prevalence of exposure among controls to lifetime preconception doses of $\geqslant 100 \mathrm{mSv}$ of $0.6 \%$ (5/890), whereas Gardner et al reported a $1 \cdot 1 \%$ prevalence ( $3 / 276$ local controls), and the prevalences of a dose of $\geqslant 10 \mathrm{mSv}$ in the six months before conception were $0.8 \%(7 / 890)$ in our study and $1 \cdot 1 \%(3 / 276)$ in the Sellafield study. Among leukaemia cases, however, such doses did not occur in our study, whereas the prevalences for both the $100 \mathrm{mSv}$ and $10 \mathrm{mSv}$ doses were $8 \cdot 7 \%(4 / 46)$ in the Sellafield study. Therefore, even though the relatively high preconception doses did occur in Ontario, this study does not support the previously reported strong associations because such exposures occurred only among the fathers of controls.

Because this study referred to a large population over a long period of time it was possible to attain a relatively large sample size, which had exposure data on more than twice the number of leukaemia cases (112) than did the Sellafield study (46). ${ }^{5}$ Nevertheless, the rarity of the exposure of primary interest compromised the ability of both studies to estimate relative risk precisely, as indicated by their wide confidence intervals. The $95 \%$ confidence interval for the odds ratio of 8.38 for the preconception dose category of $\geqslant 100 \mathrm{mSv}$ was 1.4 to 52.0 in the Sellafield study, whereas in our study the upper limit was 9.72 . For exposures of $\geqslant 10 \mathrm{mSv}$ during the six months before conception, Gardner et al found a confidence interval of 1.6 to 41.7 for an odds ratio estimate of 8.21 , whereas the upper limit from our study was $5 \cdot 86$.

The hypothesis that the observed odds ratios were equal to the values originally reported by Gardner et al was tested by calculating the probability of obtaining the observed data under the assumption that the previously reported odds ratio was the true value. For a total whole body preconception dose of $\geqslant 100 \mathrm{mSv}$ before conception, and under the assumption that the true odds ratio was $8 \cdot 38$, the probability of obtaining the observed data (no cases and five controls exposed) was $0 \cdot 101$. In contrast, the observed exposures to a total whole body dose of $\geqslant 10 \mathrm{mSv}$ during the six months before conception (no cases and seven controls) occurred with a probability of 0.008 under the assumption that the true odds ratio was 8.21. Accordingly, for the high dose category in the six months before conception ( $\geqslant 10 \mathrm{mSv}$ ) it can be concluded with a high degree of certainty $(p=0.008)$ that the odds ratio estimated in this study was less than the value of 8.21 reported by Gardner et al; however, for lifetime preconception exposures of $\geqslant 100 \mathrm{mSv}$, the possibility that the true odds ratio was 8.38 cannot be ruled out with the same high degree of certainty $(\mathrm{p}=0 \cdot 101)$.

\section{OTHER STUDIES}

Few epidemiological studies have directly examined whether preconceptional paternal radiation exposure is associated with leukaemia in offspring. The absence of such an association among Japanese bomb survivors $^{7834}$ was noted by Gardner et al, ${ }^{5}$ who proposed that the discrepancy may be due to differences in radiation dose rates or the interval between exposure and conception. Owing to the rarity of both the exposure and outcome, precise statistical results are difficult to achieve in research of this issue in any setting. For example, several studies that considered this issue have had limited statistical power and were unable to provide strong evidence either for or against the primary hypothesis. ${ }^{10-123536}$ Further- 


\section{Public health implications}

- Childhood leukaemia has been associated with the occupational exposure of fathers to ionising radiation before a child's conception

- This case-control study examined childhood leukaemia in the vicinity of nuclear facilities in Ontario in the period 1950-88 and included 112 children with leukaemia and 890 control children - Risk of leukaemia among children whose fathers had a detectable radiation dose before the child's conception was similar to the risk in children whose fathers had not been exposed

- There was no evidence of an increased risk for the exposure periods examined

- These findings do not support the hypothesis that leukaemia in offspring is associated with occupational exposures of fathers to ionising radiation before conception

more, the results of studies from Japan, ${ }^{7-8}$ the United Kingdom, ${ }^{14-15}$ and Ontario that directly examined the effects of preconceptional paternal radiation dose have not been consistent with the strong associations reported by Gardner et al. ${ }^{5}$

Another possible explanation for the discrepancies between the findings of this study and those of Gardner et al is that there may be differences in the occupational exposures of fathers in the two settings. Gardner et al proposed that Sellafield workers who received high radiation exposures may have had concomitant exposures to toxic chemicals. Benzene and other organic solvents were used in nuclear fuel reprocessing facilities in England and Scotland, ${ }^{37}$ and parental exposures to these chemicals have been previously reported as possible risk factors for childhood cancer. ${ }^{38-40}$ Most nuclear workers in Ontario are seldom exposed to toxic chemicals; therefore, it was not possible in this study to test the hypothesis regarding the leukaemogenic effect of such chemicals. On the other hand, in Ontario it was possible to examine the effect of preconception radiation exposures without the potentially confounding influence of chemical exposures.

We conclude that there was no association between childhood leukaemia and the occupational exposure of fathers to ionising radiation before the time of conception. This conclusion applies in particular to radiation exposures arising from employment in the nuclear industry in Ontario. No association was detected for external whole body dose, tritium dose, or radon exposures, or for any of the preconception or prediagnosis periods of exposure. Odds ratios were close to 1.0 for all radiation dose categories and occupations except for uranium mining, which had a large odds ratio that was not significantly different from 1.0 . Further research in this area is warranted so that a more complete assessment of consistency between studies can be conducted in the future; however, the challenge that all such studies will encounter is that statistical power may be limited due to the rarity of both the exposure and outcome.

We gratefully acknowledge the assistance of Mrs V Hunter, Ms D Nishri, Ms P Clarke, Mr R Parkes, Ms S Wing, and others in the Division of Epidemiology and Statistics of the Ontario Cancer Treatment and Research Foundation; Dr W Sont and others at the National Dose Registry, Bureau of Radiation and Medical Devices, Health and Welfare Canada; Dr D Whillans and others at Ontario Hydro; Ms M Werner, Mr B Heinmiller, and Mr S Linauskas at Atomic Energy Canada Limited; Dr V Elaguppillai, Mr J Hore, and others at the Atomic Energy Control Board; Mr R Kusiak at the
Ministry of Labour; Dr A R Belch at the Alberta Cancer Board; and Mrs C LaChapelle and staff at the Office of the Ontario Registrar General. Also appreciated were the critiques offered by many reviewers, including $\mathrm{Dr} A$ Arsenault, Dr R Cartwright, Dr G Draper, Sir R Doll, Dr G B Hill, Dr G R Howe, Dr L McIntyre, Dr D Myers, and Dr H Marshall.

1 Craft AW, Openshaw S, Birch J. Apparent clusters of childhood lymphoid malignancy in northern England. Lancet 1984;ii:96-7.

2 Gardner MJ, Hall AJ, Downes S, Terrell JD. Follow up study of children born to mothers resident in Seascale, West Cumbria (birth cohort). BMF 1987;295:822-7.

3 Gardner MJ, Hall AJ, Downes S, Terrell JD. Follow up study of children born elsewhere but attending school in Seascale, West Cumbria (school cohort). BMF 1987;295:819-22.

4 Gardner MJ, Hall AJ, Snee MP, Downes S, Powell CA, Terrell JD. Methods and basic data of case-control study of leukaemia and lymphoma among
young people near Sellafield nuclear plant in West Cumbria. BMJ 1990;300:429-34.

5 Gardner MJ, Snee MP, Hall AJ, Powell CA, Downes S, Terell JD. Results of case-control study of leukaemia and lymphoma among young people near Sellafield nuclear plant in West Cumbria. BMF 1990;300:423-9.

6 Gardner MJ. Paternal occupations of children with leukaemia. BMf 1992;305: 715.

7 Yoshimoto Y, Neel JV, Schull WJ, Kato H, Soda M, Eto R, et al. Malignant tumors during the first two decades of life in the offspring of atomic bomb survivors. Am ₹ Hum Genet 1990;46:1041-52.

8 Yoshimoto Y. Cancer risk among children of atomic bomb survivors: A review of RERF epidemiologic studies. IAMA 1990;264:596-600.

9 Little MP. The risks of leukaemia and non-cancer mortality in the offspring of the Japanese bomb survivors and a comparison of leukaemia risks with those in the offspring of the Sellafield workforce. F Radiol Prot 1992;12:203-18.

10 Urquhart JD, Black RJ, Muirhead JM, Sharp L, Maxwell M, Eden OB, et al. Case-control study of leukaemia and non-Hodgkin's lymphoma in children in Caithness near the Dounreay nuclear installation. BMf 1991;302:687-92.

11 McKinney PA, Alexander FE, Cartwright RA, Parker L. Parental occupation of children with leukaemia in West Cumbria, North Humberside and Gateshead. $B M \mathcal{F}$ 1991;302:681-7.

12 Alexander FE, Cartwright RA, McKinney PA. Paternal occupations of children with leukaemia. $B M \mathcal{F}$ 1992;305:715-6.

13 Sorahan T, Roberts PJ. Childhood cancer and paternal exposure to ionizing radiation: preliminary findings from the Oxford Survey of Childhood Cancers. Am F Indust Med 1993;23:343-54.

14 Roman E, Watson A, Beral V, Buckle S, Bull D, Baker K, et al. Case-control study of leukaemia and non-Hodgkin's lymphoma among children aged 0-4 years living in West Berkshire and North Hampshire health districts. $B M \mathcal{F}$ 1993;306:615-21.

15 Kinlen LJ, Clarke K, Balkwill A. Paternal preconceptional radiation exposure in the nuclear industry and leukaemia and non-Hodgkin's lymphoma in young people in Scotland. BMF 1993;306:1153-8.

16 McLaughlin JR, Clarke EA, Nishri D, Anderson TW. Childhood leukaemia in the vicinity of Canadian nuclear facilities. Cancer Causes Control 1993;4:51-8.

17 Ashmore JP, Grogan D. The National Dose Registry for radiation workers in Canada. Radiat Prot Dosim 1985;11:95-100.

18 Ontario Hydro, Radioactivity Management and Environmental Protection Department. Nuclear generating division occupational radiation dose summary 1962 to 1978. Toronto: Ontario Hydro, 1980.

19 World Health Organisation, Ninth Revision Conference, 1975. Manual of the international statistical classification of diseases, injuries, and causes of death. Vol 1. Geneva: WHO, 1977.

20 Statistics Canada. Census of Canada, Ontario: part 2, profiles-population and dwelling characteristics-census divisions and subdivisions. Ottawa: Ministry of Supplies and Services, Canada, 1986.

21 Doll R. The epidemiology of childhood leukaemia. $f R$ Statist Soc $[A]$ 1989;152:341-51.

22 Linet MS, Devesa SS. Descriptive epidemiology of childhood leukaemia. Brf Cancer 1991;63:424-9.

23 Stiller CA. Descriptive epidemiology of childhood leukaemia and lymphoma in Great Britain. Leukaemia Res 1985;9:671-4.

24 Courot M, Hochereau-de Reviers MT, Ortavant R. Spermatogenesis. In: Johnson AD, Gomes WR, Vandemark NL, eds. The testis. New York: Academic Press, 1970:390.

25 Muller J, Wheeler WC, Gentleman JF, Suranyi G, Kusiak RA. Study of morality of Ontario miners: 1955-1977. Toronto: Ontario Ministry of Labour, 1983 .

26 EGRET. Seattle: Statistics and Epidemiology Research Corporation, 1991.

27 LogXact. Cambridge, Massachusetts: CYTEL Software Corporation, 1993.

27 LogXact. Cambridge, Massachusetts: CYTEL Software Corporation, 1993. Breslow NE, Day NE. Statistical methods in cancer research. Vol I. The analysis
of case-control studies. Lyons: International Agency for Research on Cancer, 1980:125.

29 McLaughlin JR, Anderson TW, Clarke EA, King W. Occupational exposure of fathers to ionizing radiation and the risk of leukaemia in offspring: a case-control study. Ottawa: Atomic Energy Control Board, 1992.

30 Henshaw DL, Eatough JP, Richardson RB. Radon as a causative factor in induction of myeloid leukaemia and other cancers. Lancet 1990;335: 1008-12.

31 Committee on the Biological Effects of Ionizing Radiations. Health risks of radon and other internally deposited alpha-emitters-BEIR IV. Washington, DC: National Academy of Science, 1988:492.

32 Robles SC, Marrett LD, Clarke EA, Risch HA. An application of capturerecapture methods to the estimation of completeness of cancer registration. fClin Epidemiol 1988;41:495-501.

33 Clarke EA, Marrett LD, Kreiger N. Twenty years of cancer incidence, 1964-1983. Toronto: Ontario Cancer Treatment and Research Foundation, 1987:11.

34 Little MP. The risks of leukaemia and non-cancer mortality in the offspring of the Japanese bomb survivors and a comparison of leukaemia risks with those in the offspring of the Sellafield workforce. F Radiol Prot 1992;12:203-18.

35 Little MP. A comparison of the risks of childhood leukaemia from parental preconception exposure to radiation in the Sellafield and Dounreay workforces and the Japanese bomb survivors. $f$ Radiol Prot 1991;11:231-40. 
36 Michaelis J, Keller B, Haaf G, Kaatsch P. Incidence of childhood malignancies in the vicinity of West German nuclear power plants. Cancer Causes Control 1991:3:255-63.

37 Committee on Medical Aspects of Radiation in the Environment. Second report: investigation of the possible increased incidence of leukaemia in young people near the Dounreay nuclear establishment, Caithness, Scotland. London HMSO, 1988.

38 Fabia J, Thuy TD. Occupation of father at time of birth of children dying of malignant diseases. Br f Prev Soc Med 1974;28:98-100.
39 Lowengert RA, Peters JM, Cicioni C, Buckley J, Bernstein L, Preston-Martin $S$, et al. Childhood leukaemia and occupational and home exposures. 7 Natl Cancer Inst 1987;79:39-46.

40 Buckley JD, Robison LL, Swotinsky R, Garabrant DH, LeBeau M, Manchester $\mathrm{P}$, et al. Occupational exposures of parents of children with acute nonlymphocytic leukaemia: a report from the Childen's Cancer Stud Group. Cancer Res 1989;49:4030-7.

\title{
Geographical distribution of preconceptional radiation doses to fathers employed at the Sellafield nuclear installation, West Cumbria
}

\author{
Louise Parker, Alan W Craft, Julian Smith, Heather Dickinson, Richard Wakeford, Keith Binks, \\ Damien McElvenny, Les Scott, Andy Slovak
}

\begin{abstract}
Objective-To examine whether the geographical distribution of births associated with preconceptional exposure of fathers to radiation at the Sellafield nuclear installation is consistent with the suggestion that this exposure explains the excess of childhood lymphoid malignancy in the adjacent village of Seascale.

Design-Retrospective birth cohort study.

Setting-Cumbria, West Cumbria health district, and Seascale civil parish.

Subjects-The 10363 children born in Cumbria
\end{abstract} during 1950-89 to fathers employed at Sellafield.

Main outcome measures-The doses of external whole body ionising radiation received by fathers at Sellafield in the total time and in the six months before conception of their children; the proportions of the collective doses associated with Seascale and the rest of West Cumbria.

Results -9256 children were born to fathers who had been exposed to radiation before the child's conception. Of these, 7318 had fathers who were exposed in the six months before conception. Overall 7\% (38 person-Sv) of the collective total preconceptional dose and $7 \%$ (3 person-Sv) of the collective dose for the six months before conception were associated with children born in Seascale. Of all the children whose fathers worked at Sellafield, $842(8 \%)$ were born in Seascale. The mean individual doses before conception were consistently lower in Seascale than in the rest of West Cumbria.

Conclusions-The distribution of the paternal preconceptional radiation dose is statistically incompatible with this exposure providing a causal explanation for the cluster of childhood leukaemias in Seascale.

\section{Introduction}

The excess incidence of childhood leukaemia in the coastal village of Seascale, West Cumbria, has received much attention. Gardner et al conducted a case-control study of leukaemia and lymphoma among young people in West Cumbria. ${ }^{12}$ They concluded that there is a statistically significant excess of leukaemia among children whose fathers received fairly high doses of external whole body ionising radiation while employed at the Sellafield nuclear installation before the conception of their children. They suggested that the statistical association between these doses and childhood leukaemia was sufficient in itself to account for the excess leukaemia in children born and diagnosed in Seascale. If this were so paternal preconceptional radiation doses would be concentrated in fathers of children born in Seascale as there is no general excess of childhood leukaemia in the rest of West Cumbria.

We examined whether the geographical distribution of this putative risk factor (paternal preconceptional radiation exposure) in Cumbria is compatible with that of cases of leukaemia among children associated with such exposure.

\section{Subjects and methods}

We compiled a database of Cumbrian children born between 1950 and 1989 to fathers who worked at Sellafield. The year 1950 was taken as the start of the period of interest as it was then that nuclear operations started at Sellafield. ${ }^{3}$

All births registered in the geographical region currently defined by the county of Cumbria (fig 1) (except for a small area for the period 1974-89, which was in Cumberland up to 1974 but is now in North Yorkshire and has about 10 births a year) during the period 1950-89 were identified by means of the register of live births, which was supplied on microfilm by the Office of Population Censuses and Surveys.

All information pertaining to the registered child and his or her parents recorded by the birth certificates was entered on a database by using a Macintosh computer system and the database package 4th Dimension. ${ }^{4}$ The residential address at birth of the mother of each child, as reported on the birth certificate, was assigned a postcode manually from postcode

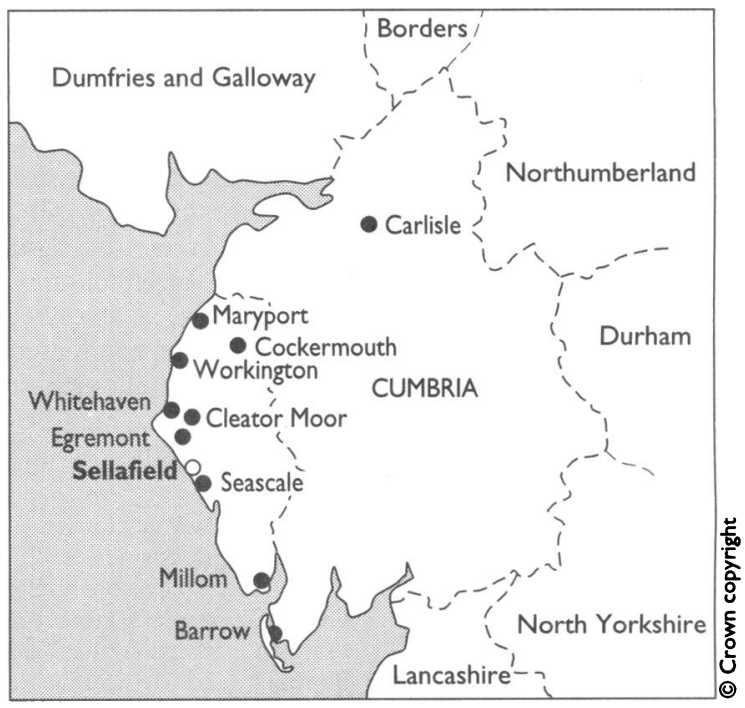

FIG 1-County of Cumbria, England, showing Sellafield nuclear installation and main settlements containing residences of children born installation and main settlements containing residences of children born Cumbria Health Authority and of Seascale civil parish are also shown 